\title{
Integrative analysis for finding genes and networks involved in diabetes and other complex diseases Regine Bergholdt*, Zenia M Størling ${ }^{\star \dagger}$, Kasper Lage $^{\star \dagger}$, E Olof Karlberg ${ }^{\dagger}$, Páll Í Ólason ${ }^{\dagger}$, Mogens Aalund ${ }^{\ddagger}$, Jørn Nerup*${ }^{*}$, Søren Brunak ${ }^{\dagger}$, Christopher T Workman ${ }^{\dagger}$ and Flemming Pociot ${ }^{*} \S$
}

\author{
Addresses: *Steno Diabetes Center, Niels Steensensvej 2, DK-2820 Gentofte, Denmark. ${ }^{\dagger}$ Center for Biological Sequence Analysis, Technical \\ University of Denmark, DK-280o Lyngby, Denmark. ${ }^{\star}$ Neurotech A/S, DK-210o Copenhagen, Denmark. §Institute for Clinical Science, \\ University of Lund, SE-221 oo Lund, Sweden. \\ $\bowtie$ These authors contributed equally to this work. \\ Correspondence: Flemming Pociot. Email: fpoc@steno.dk \\ Published: 28 November 2007 \\ Genome Biology 2007, 8:R253 (doi:10.1 I86/gb-2007-8-II-r253) \\ The electronic version of this article is the complete one and can be \\ found online at http://genomebiology.com/2007/8/I I/R253 \\ Received: 7 July 2007 \\ Revised: 31 October 2007 \\ Accepted: 28 November 2007 \\ (c) 2007 Bergholdt et al.; licensee BioMed Central Ltd. \\ This is an open access article distributed under the terms of the Creative Commons Attribution License (http://creativecommons.org/licenses/by/2.0), which \\ permits unrestricted use, distribution, and reproduction in any medium, provided the original work is properly cited.
}

\begin{abstract}
We have developed an integrative analysis method combining genetic interactions, identified using type I diabetes genome scan data, and a high-confidence human protein interaction network. Resulting networks were ranked by the significance of the enrichment of proteins from interacting regions. We identified a number of new protein network modules and novel candidate genes/ proteins for type I diabetes. We propose this type of integrative analysis as a general method for the elucidation of genes and networks involved in diabetes and other complex diseases.
\end{abstract}

\section{Background}

Complex traits like type 1 diabetes (T1D) are generally believed to be under the influence of multiple genes interacting with each other to confer disease susceptibility and/or protection. Identification of susceptibility genes in complex genetic diseases, however, poses many challenging problems. The contribution from single genes is often limited and genetic studies generally do not offer clues about the functional context of a gene associated with a complex disorder. A recent report demonstrated the feasibility of constructing functional human gene networks (using, for example, expression and Gene Ontology (GO) data [1]), and using these in prioritizing positional candidate genes from non-interacting susceptibility loci for various heritable disorders [2]. It was shown that the obvious candidate genes were not always involved, and that taking an unbiased approach in assessing candidate genes using functional networks may result in new, non-obvious hypotheses that are statistically significant.

One of the strongest indications of functional association is the presence of a physical interaction between proteins [3] and several reports have shown that proteins involved in the same phenotype are likely to be part of the same functional module (that is, protein sub-network) [4-6]. With this in mind, it seems reasonable to expect that, in many cases, components contributing to the same complex diseases will be members of the same functional modules, especially if the disease is associated with multiple genetic loci that show statistical indication for epistasis. This indicates that in the case of complex disorders a feasible strategy would be to search for groups of interacting proteins that together lead to significant association with the disease in question. However, a strategy 
searching for loci showing genetic interaction (epistasis) integrated with a search for protein networks spanning the epistatic regions and subsequent significance ranking of these networks has, to our knowledge, never been pursued for any complex disorder.

Presumably, this is because a number of problems are associated with such a strategy. First, traditionally genetic linkage analysis is performed by searching for the marginal effect of a single putative trait locus, whereas methods for searching for multiple trait loci simultaneously are limited [7-11], and in T1D statistical indication for epistasis has been shown only for a few candidate loci [10,12,13]. Secondly, an insufficient amount of human protein interaction data has precluded systematic analyses of protein networks enriched for proteins originating from interacting genomic regions. Moreover, no single database houses all human protein interaction data, and the data are generally noisy, containing many false positive interactions [4]. Thirdly, no standard statistical method for measuring the significance of protein networks, based on the enrichment of proteins from genetically interacting regions, has yet been reported.

We addressed these issues through a number of approaches. First, data mining/decision trees were used to identify genetic markers or combinations of markers of predictive value for T1D. This approach is well suited to handle the complexity of genetic data, and has been proven to be able to precisely identify risk loci associated with $\mathrm{T} 1 \mathrm{D}$, as well as interacting genetic regions [14-18]. In the present study we have tested whether identical-by-descent (IBD) sharing data [19-21], instead of exact allele-calling genotypes as previously used [18], could be used to identify risk loci. The data analyzed were from the published T1D genome scans [22,23] available through the Type 1 Diabetes Genetics Consortium (T1DGC) [24]. We have recently constructed a high-confidence human protein interaction network by extensive data integration, including conservative incorporation of data from model organisms, followed by rigorous quality scoring of the protein interactions [4]. This network was searched for protein networks enriched in proteins from the interacting genetic regions demonstrated. Subsequently, we developed a new statistical method for evaluating the significance of this enrichment, which enabled us to rank all identified networks. The strategy used is outlined in Figure 1.

Several significant networks were identified. Some of the candidates in these networks were known HLA (human leukocyte antigen) region (chromosome 6p21) genes, including the recently identified $\mathrm{T} 1 \mathrm{D}$ associated candidate gene $I T P R_{3}$, which was centrally located in one of the top scoring networks. However, some significant networks contained protein components that have never been associated with T1D. Since all candidates identified in the present work were put in a functional context with other members of a network (guiltby-association), the networks immediately offer clues on the functional role of the candidates and other proteins in relation to T1D. Our observations support that genetic interactions are important in T1D susceptibility, and that an integration of genetic and physical interactions is an interesting new approach for analyzing complex disorders.

\section{Results \\ Marginal markers}

In the total data set of 1,321 affected sibling pair families from the UK, the US and Scandinavia, data mining/decision tree analyses identified major T1D predictive signals (marginal markers; Table 1) corresponding to T1D linkage signals found by classic non-parametric linkage analysis [25]. As the original T1DGC publication [25] included data on 254 additional affected sibling-pair families not part of the present analyses, direct comparison of results is not possible. However, substantial agreement existed between the analyses (Table 1). Ranking of markers is according to their T1D predictive signal determined by Pearson's $\chi^{2}$ statistics and corresponding $P$ value. As we evaluated only a limited number of the genotyped markers in the total data set, we endeavored to see if supplementary information could be extracted from more complete subsets of data (UK/US and Scandinavian). As seen in Table 1, the group of markers corresponding to the HLA region shows a much higher predictive signal (by several orders of magnitude) than the rest of the markers. $D 6 S 283$ and D6S3Oo are markers for IDDM15 (6q21) [26], which in linkage studies generally require separate analysis to differentiate its effect from MHC $[25,26]$. Markers for the regions 2q31-q33, 16p12-q11.1, 11p15.5, 16q22-q24 and 10p14-q11 identified by linkage analysis [25] also showed high predictive signals in the current study, either in the total data set or in the data subsets (Table 1). In addition, a few new markers were found to show predictive signals $(P<0.05)$ when evaluated independently of chromosome 6 markers, for example, D17S798, D2S125, D9S175, D8S261 and D4S403. The D21S27o marker was identified in the Scandinavian subset and corresponds to a T1D linkage region on chromosome 21, which we have recently identified and fine mapped [22,27]. In the UK/US data set, the 2q31-q33 region (the CTLA4 region) seems of higher predictive value than in the total data set (Table 1). D4S4O3 corresponds to a region previously linked to $\mathrm{T} 1 \mathrm{D}[22,28]$ containing the WFS1 gene associated with Wolfram syndrome (MIM \#222300), which involves T1D [28].

\section{Epistasis}

The importance of HLA is well established, and we are, by the methods used here, able to evaluate important markers in sibling pairs sharing just one HLA allele. The top scoring marginal marker for the HLA region was the tumor necrosis factor alpha (TNFA) micro satellite marker, located centrally in the HLA region. To determine candidates for the next level, we searched for interacting markers with the HLA region, in the subgroups of sibling pairs with TNFA IBD status $=1$ 


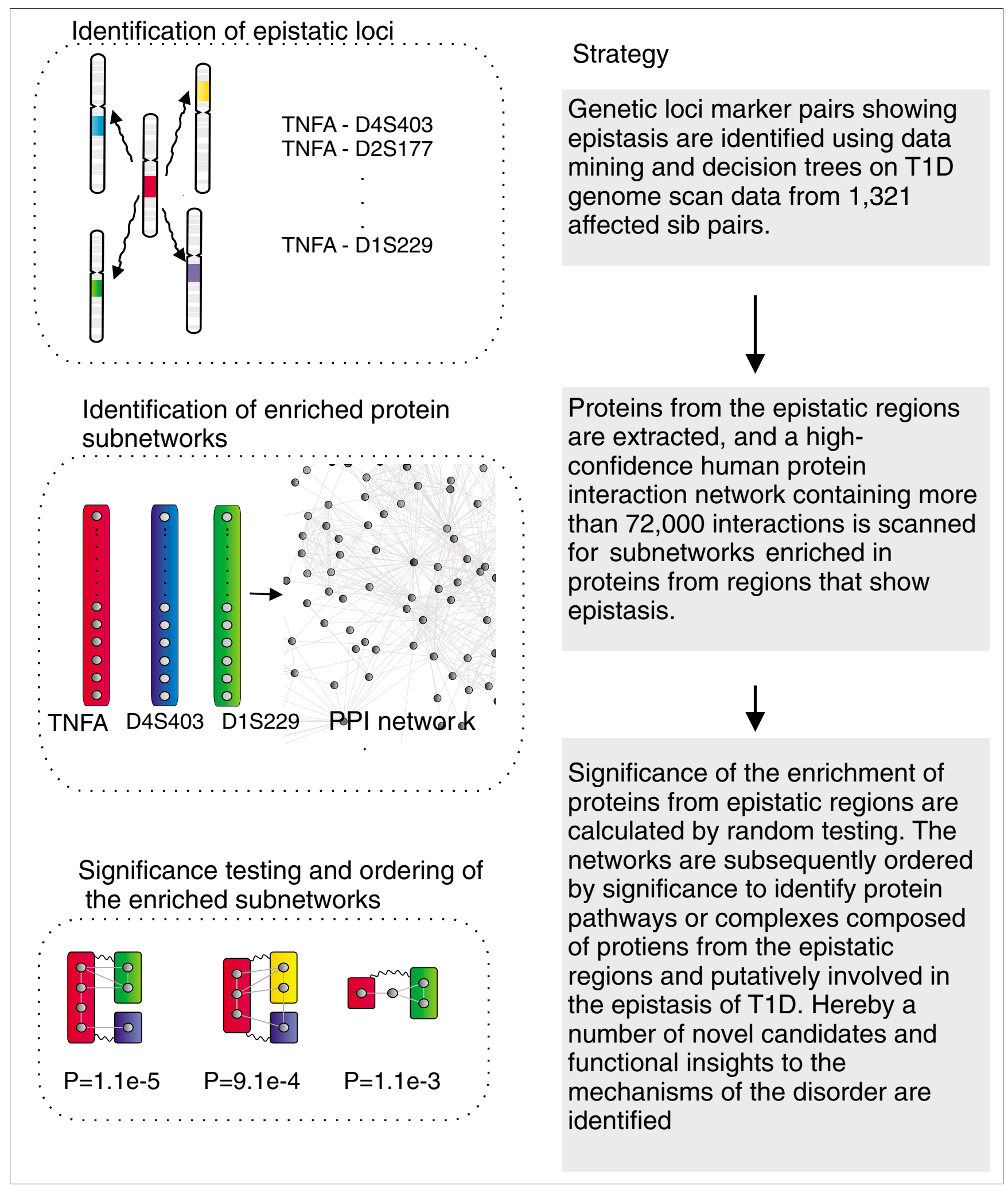

Figure I

The strategy used for the current study. 
Table I

\begin{tabular}{|c|c|c|c|c|}
\hline & $\chi^{2}(2$ d.f. $)$ & $P$ value & $\begin{array}{l}\text { Position on } \\
\text { chromosome in cM }\end{array}$ & $\begin{array}{l}\text { Confirmed from genome scan } \\
\text { LOD - I interval) or other references }\end{array}$ \\
\hline \multicolumn{5}{|l|}{ Total data set } \\
\hline TNFA & 142.0 & $1.5 \times 10^{-32}$ & 47 & 6p2I (46-48 cM) [25] \\
\hline D6S273 & 77.0 & $7.0 \times 10^{-18}$ & 45 & \\
\hline D6S29I & 58.2 & $2.2 \times 10^{-13}$ & 49.5 & \\
\hline D6S276 & 34.8 & $3.4 \times 10^{-8}$ & 44.4 & \\
\hline D6S260 & 27.1 & $8.2 \times 10^{-7}$ & 29.9 & \\
\hline D6S286 & 21.4 & $1.6 \times 10^{-5}$ & 89.8 & \\
\hline D6S283 & 18.3 & 0.0001 & 109.2 & [26] \\
\hline D6S470 & 15.2 & 0.0005 & 18.2 & \\
\hline D6S300 & 10.6 & 0.005 & 103.5 & {$[26]$} \\
\hline DI7S798 & 9.8 & 0.007 & 53.4 & \\
\hline $\mathrm{D} 2 \mathrm{~S} 152$ & 8.7 & 0.013 & 188.1 & $2 q 31-33(177-204 c M)$ [25] \\
\hline $\mathrm{D} 2 \mathrm{~S} 125$ & 7.0 & 0.03 & 260.6 & \\
\hline D9SI75 & 6.3 & 0.043 & 70.3 & \\
\hline D8S26I & 6.1 & 0.048 & 37.0 & \\
\hline D4S403 & 6.1 & 0.048 & 25.9 & \\
\hline \multicolumn{5}{|c|}{ Selected markers } \\
\hline \multicolumn{5}{|l|}{ UK/US subset } \\
\hline D2S389 & 13.1 & 0.001 & 190 & $2 q 31-33(177-204 \mathrm{cM})[25]$ \\
\hline DI6S769 & 9.4 & 0.009 & 50.6 & $|6 p| 2-q|| . \mid(26-7 \mid c M)[25]$ \\
\hline Thl & 9.0 & 0.011 & 5.9 & IIpI5.5 (0-14 cM) [25] \\
\hline DI6S289 & 8.1 & 0.017 & 105 & $16 q 22-q 24(100-121$ cM) [25] \\
\hline DIOSI83 & 6.7 & 0.035 & 60.6 & I0p|4-q|I (52-66 cM) [25] \\
\hline \multicolumn{5}{|c|}{ SCAND subset } \\
\hline $\mathrm{D} 21 \mathrm{~S} 270$ & 6.4 & 0.039 & 38.1 & {$[27]$} \\
\hline
\end{tabular}

Markers of predictive value for TID identified by decision tree analysis on TID genome scan data from I32I affected sib pair families. Markers identified in the total data set are ranked according to significance level $(P<0.05)$. Markers from data subsets are 'selected markers' and were selected on basis of whether they confirm loci from the latest TID genome scan [25] or other references [26; 27]. D.f. = degrees of freedom.

$(T N F A=1)$ and TNFA IBD status $=2(T N F A=2)$, respectively. No interactions with $T N F A=0$ could be generated due to the low number of affected sibling pairs in this group. Specific combinations of markers corresponding to statistically significant genetic interactions in the combined data set are shown in Table 2. The marker combination TNFA $=1-$ D11S910 was shown to be of protective value, since sibling pairs sharing one TNFA allele, but two alleles of D11S91O, were strongly protected against T1D (of 25 sibling pairs with this combination, one was concordant for T1D, 24 were nonT1D). The other combinations of markers detected implied increased susceptibility to T1D. None of the interacting markers from Table 2, except $\mathrm{D}_{4} \mathrm{~S} 4 \mathrm{O} 3$, correspond to previously known regions associated with T1D [29].

Genetic interaction analysis was performed for the marginal markers with the highest predictive signals, and was also performed independent of HLA (TNFA) IBD sharing status.
When evaluating epistasis independent of HLA, we searched specifically for epistasis between the three highest ranking markers, D17S798, D2S152 and D2S125, after chromosome 6 markers were removed. In the combined data set, however, only combinations including the marker on chromosome 17 predicted genetic interaction (that is, $D_{17} S_{798}=1-D_{5} S 429$ $(P=0.029)$ and $D 17 S 798=1-D 1 S 197(P=0.031)$, and between $\left.D_{17} S_{798}=2-D 2 P 25(P=0.041)\right)$. These combinations reached statistical significance, and demonstrated increased susceptibility to T1D (Table 2). Relationships could only be inferred for two markers at a time due to the high number of missing and non-informative values for many markers.

\section{Protein interaction networks}

We searched for protein networks spanning the regions shown to interact genetically ( $P$ values $<0.05$; Table 2$)$. This was performed using a high-confidence human protein inter- 
Table 2

\begin{tabular}{|c|c|c|c|}
\hline First level & Second level & Pearson's $\chi^{2}$ (2 d.f.) & $P$ value \\
\hline TNFA $=2$ & D4S403 & 9.10 & 0.011 \\
\hline TNFA $=2$ & $\mathrm{D} 2 \mathrm{~S} 177$ & 7.33 & 0.026 \\
\hline TNFA $=2$ & DIS229 & 6.88 & 0.032 \\
\hline TNFA $=1$ & DIIS9I0 & 11.82 & 0.0027 \\
\hline TNFA $=1$ & DI3SI70 & 6.84 & 0.033 \\
\hline TNFA $=1$ & DI6S287 & 6.63 & 0.036 \\
\hline D $17 S 798=2$ & $\mathrm{D} 2 \mathrm{P} 25$ & 6.41 & $0.04 I$ \\
\hline $\mathrm{D} 17 \mathrm{~S} 798=1$ & D5S429 & 7.08 & 0.029 \\
\hline $\mathrm{D} 17 \mathrm{~S} 798=1$ & DISI97 & 6.94 & 0.031 \\
\hline
\end{tabular}

Markers corresponding to the first and second level of each significant interaction, as well as Pearson $\chi^{2}$ statistics and corresponding $P$ value, are shown. Affected sibling pairs (ASPs) genotyped for the TNFA and DI7S798 marker were as follows (non-TID sibling pairs were simulated to be twice the number of ASPs for each group): TNFA = 2, 520 ASP and I,040 non-TID sibling pairs; TNFA = I, 206 ASP and 4 I 2 non-TID sibling pairs; DI7S798 = 2, I 36 ASP and 272 non-TID sibling pairs; DI7S798 = I, 254 ASP and 508 non-TID sibling pairs.

action network [4]. Input proteins were proteins corresponding to a defined genetic region surrounding the interacting markers included in the different marker combinations. For all markers except TNFA, $5 \mathrm{Mb}$ on each side of the marker in question was used as input. This region size was selected since linkage peaks (LOD - 1 intervals) from genome scans that use a similar number of markers often corresponded to regions of this size. For the HLA region, we have exclusively used the classic MHC region (4 Mb) for analysis, due to the well examined nature of this region with a high degree of linkage disequilibrium, as well as the large number of genes clustered in this specific region [30]. The classic MHC region comprises the TNFA marker in a central position (positioned at bases $31,643,403-31,643,437$ on the physical map of chromosome 6, corresponding to $46.7 \mathrm{cM}$ ).

We were able to identify 22 protein sub-networks that connect proteins from the different regions corresponding to the significant two-marker predicted genetic interactions. The union of these sub-networks resulted in 13 putative functional modules (Figure 2).

\section{Network significance analysis}

The significance of each putative functional module was assessed by comparison to search results for randomly selected genetic regions. This assessment was made for both the results of marker-region pairs (2-interval) and for the resulting merged modules containing genes from two or more intervals ( $k$-interval). Four 2-interval modules that included TNFA-region genes, two of which were found to be significant, were merged into a single highly significant 5 -interval module (Figure 3, module A). This concordance strongly suggests that the four TNFA-region genes TUBB, RPS18, ITPR3 and $B A T 1$ may be important in explaining the mechanism of the four genetic interactions. From the interacting chromosomal regions, the WDR1, LMO7, HNRPLL and RPS15A genes are potential T1D candidate genes. These genes are involved in transcriptional regulation, DNA binding, RNA binding, ion channel activity, ATP synthesis, actin binding and natural killer cell mediated cytotoxicity and cell proliferation. Candidate genes from the four significant functional modules (Figure 3) are listed in Table 3. Other networks with TNFA include genes involved in signal transduction, regulation of transcription, protein biosynthesis and folding, histone activity, ubiquitin-protein ligase activity, as well as response to oxidative stress (Table 3 ), also of potential relevance in $\mathrm{T} 1 \mathrm{D}$ pathogenesis.

A region on chromosome 17 also conferred a high predictive value for T1D and was found to have genetic interactions with three other marker regions. Searches conducted for genes from the three marker pairs (D17S798-D2P25, D17S798$D_{5} S_{429}$ and $\left.D_{17} S 798-D_{1} S_{197}\right)$ resulted in six putative functional modules after the initial results were combined (Figure 2). Several of the proteins in these networks are involved in signal transduction, anti-apoptosis, RNA binding regulation of transcription, kinase activity, oxidoreductase activity, DNA and ATP binding as well as oxygen transporter activity (Table 3), making them potentially important in T1D pathogenesis. One of these modules (Figure 3, module D) was found to be significant $(P<0.05)$ and contained protein interactions between members of three genetic interaction marker pairs. GO terms for molecular function and biological process for all candidate genes in significant functional modules are listed in Table 3. These findings shed light on the pathways the candidate genes in these two regions are likely to be involved in, and may help in understanding the possible effect in T1D suggested by this interaction.

\section{Discussion}

Identifying genes in multi-factorial diseases is difficult. Studies in model organisms suggest that epistasis may play an important role in the etiology of multifactorial diseases and 


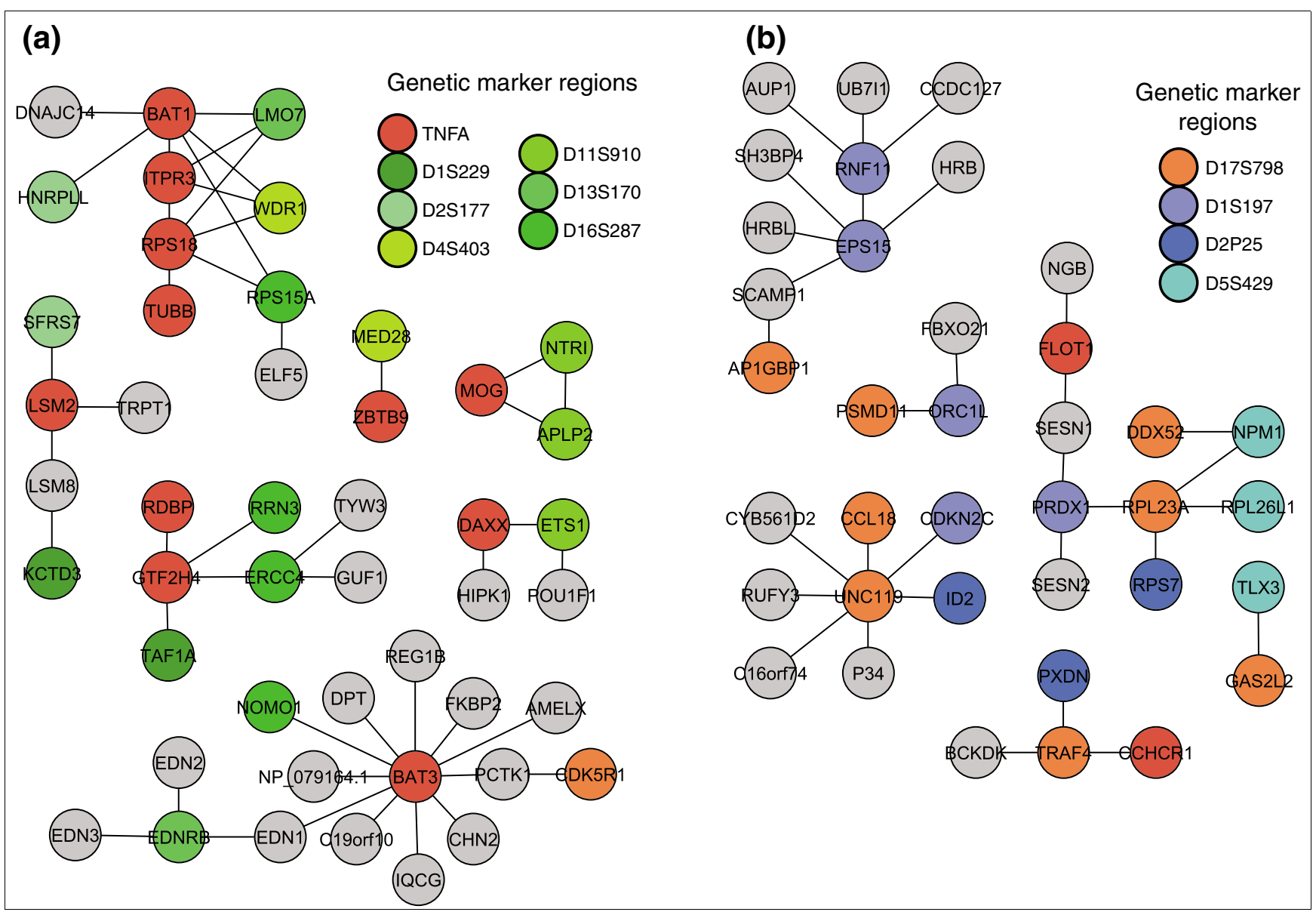

Figure 2

Protein interaction networks for predicted genetic interactions. (a) TNFA-D4S403, TNFA-DI3SI 70 and TNFA-D2SI 77 are represented by one network, whereas TNFA-DIS229, TNFA-DI6S287 and TNFA-DIIS910 are represented by two or three networks. Color-code: red, genes from TNFA region; green and yellow, genes from interacting region; light grey, genes from other chromosomes. (b) Protein interaction networks involving DI7S798. DI 7S798DIS197, DI7S798-D2P25 and DI7S798-D5S429 are represented by four, three and two networks, respectively. Color-code: red, genes from DI 7S798region; blue/green, genes from interacting region; light grey, genes from other chromosomes.

complex traits in humans. There is no consensus as to the best strategy for detecting epistatic interactions in humans [31,32]. Several recent studies in humans and animals have identified loci that interact significantly but contribute little or with no effect individually [33-35]. In T1D, attempts to elucidate possible epistasis between classic T1D loci in humans, as well as animal models, have provided only a few examples $[10,12,13]$. This highlights the need for new methods in detecting and characterizing epistasis, as well as elucidating the presumed underlying biological interactions [31,32]. In the present study we confirmed that the application of data mining methods identified most major signals (marginal markers) found using classic non-parametric linkage analysis [25]. A special feature of the methods used in the current study is that interactions can be generated with marker IBD = 1 and IBD = 2 status. No marker combination with marker IBD $=0$ could be generated (due to a low number of affected sibling pairs in this group).
We demonstrated several significant interactions between two different markers predictive for increased susceptibility to $\mathrm{T} 1 \mathrm{D}$ and one rule $(T N F A=1-D 11 S 910)$, which predicted protection against T1D. Generation of specific combinations of markers between different chromosomal regions supports that interaction is important in complex diseases like T1D. A number of recent efforts have combined linkage mapping with the identification of co-regulated genes using microarrays to discover trans-acting expression quantitative trait loci [36-39]. While this may be a promising approach also for identifying epistatic susceptibility genes in multifactorial diseases like $\mathrm{T} 1 \mathrm{D}$, data for combined genetic and gene expression studies in T1D are still limited.

In our effort to identify the cellular systems underlying the genetic interactions, we constructed protein sub-networks that spanned the interacting regions to investigate whether the gene products in these regions could be shown to physi- 
Table 3

Genes corresponding to protein interactions in the four statistically significant functional modules A, B, C and D (in Figure 3)

\begin{tabular}{|c|c|c|c|}
\hline Gene name & Chromosomal band & Description & GO term \\
\hline \multicolumn{4}{|l|}{ Module A } \\
\hline DNAJCI 4 & {$[|2 q| 3.2]$} & $\begin{array}{l}\text { Nuclear protein Hcc-I (Proliferation associated } \\
\text { cytokine-inducible protein CIP29) }\end{array}$ & Heat shock protein binding, unfolded protein binding \\
\hline HNRPLL & {$[2 p 22.1]$} & $\begin{array}{l}\text { Heterogeneous nuclear ribonucleoprotein L-like } \\
\text { (Stromal RNA-regulating factor) }\end{array}$ & Nucleotide binding, RNA binding, mRNA processing \\
\hline BATI & [6p21.33] & $\begin{array}{l}\text { Spliceosome RNA helicase BATI (HLA-B associated } \\
\text { transcript-I) }\end{array}$ & $\begin{array}{l}\text { Nucleotide binding, nucleic acid binding, ATP- } \\
\text { dependent RNA helicase activity, nuclear mRNA } \\
\text { splicing, mRNA export from nucleus, ATP } \\
\text { biosynthetic process, ion transport }\end{array}$ \\
\hline ITPR3 & {$[6 \mathrm{p} 21.31]$} & Inositol I,4,5-trisphosphate receptor type 3 & $\begin{array}{l}\text { lon channel activity, calcium channel activity, calcium } \\
\text { ion transport, protein binding, signal transduction }\end{array}$ \\
\hline RPSI8 & [6p21.32] & $40 \mathrm{~S}$ ribosomal protein SI8 (Ke-3) & $\begin{array}{l}\text { RNA binding, structural constituent of ribosome, } \\
\text { rRNA binding, translation }\end{array}$ \\
\hline TUBB & [6p21.33] & Tubulin beta- 2 chain & $\begin{array}{l}\text { Nucleotide binding, GTPase activity, cell motility, } \\
\text { natural killer cell mediated cytotoxicity }\end{array}$ \\
\hline LMO7 & [13q22.2] & $\begin{array}{l}\text { LIM domain only protein } 7 \text { (LOMP) (F-box only } \\
\text { protein 20) }\end{array}$ & $\begin{array}{l}\text { Protein ubiquination, actomyosin structure and } \\
\text { biogenesis, protein binding, ion binding }\end{array}$ \\
\hline WDRI & {$[4 p \mid 6.1]$} & WD repeat domain I (WDRI), transcript variant I & $\begin{array}{l}\text { Actin binding, protein binding, sensory perception of } \\
\text { sound }\end{array}$ \\
\hline RPSI5A & {$[|6 p| 2.3]$} & $40 \mathrm{~S}$ ribosomal protein $\mathrm{SI} 5 \mathrm{a}$ & $\begin{array}{l}\text { Protein binding, structural constituent of ribosome, } \\
\text { translation }\end{array}$ \\
\hline ELF5 & {$[|| p \mid 3]$} & $\begin{array}{l}\text { ETS-related transcription factor Elf-5 (E74-like factor } \\
\text { 5) }\end{array}$ & $\begin{array}{l}\text { Transcription factor activity, sequence-specific DNA } \\
\text { binding, regulation of transcription, cell proliferation }\end{array}$ \\
\hline \multicolumn{4}{|l|}{ Module B } \\
\hline$R D B P$ & {$[6 p 21.3]$} & RD RNA-binding protein, MHC complex gene RD & $\begin{array}{l}\text { RNA binding, nucleotide binding, transcription, } \\
\text { regulation of transcription }\end{array}$ \\
\hline GTF2H & {$[2 q \mid 4.3]$} & $\begin{array}{l}\text { Basic transcription factor } 289 \mathrm{kDa} \text { subunit, DNA } \\
\text { excision repair protein ERCC-3 }\end{array}$ & $\begin{array}{l}\text { DNA binding, ATP-dependent DNA helicase activity, } \\
\text { transcription-coupled nucleotide-excision repair, } \\
\text { regulation of transcription }\end{array}$ \\
\hline RRN3 & {$[|6 p| 3.1 \mid]$} & $\begin{array}{l}\text { RNA polymerase I-specific transcription initiation } \\
\text { factor }\end{array}$ & $\begin{array}{l}\text { RNA polymerase I transcription factor activity, } \\
\text { regulation of transcription }\end{array}$ \\
\hline ERCC4 & {$[16 \mathrm{p} \mid 3.12]$} & $\begin{array}{l}\text { DNA excision repair protein, DNA repair } \\
\text { endonuclease }\end{array}$ & $\begin{array}{l}\text { DNA binding, magnesium ion binding, nucleotide } \\
\text { excision repair }\end{array}$ \\
\hline TAFIA & {$[|q 4|]$} & $\begin{array}{l}\text { TATA box binding protein (TBP)-associated factor, } \\
\text { RNA polymerase I }\end{array}$ & $\begin{array}{l}\text { DNA binding, RNA polymerase I transcription factor } \\
\text { activity, regulation of transcription }\end{array}$ \\
\hline TYW3 & {$[|p 3| . \mid]$} & tRNA-yW synthesizing protein 3 homolog & None \\
\hline GUFI & {$[4 p \mid 3]$} & $\begin{array}{l}\text { GTP-binding protein GUFI homolog, GTPase of } \\
\text { unknown function }\end{array}$ & $\begin{array}{l}\text { Nucleotide binding, translation initiation factor } \\
\text { activity, GTPase activity, small GTPase mediated } \\
\text { activity }\end{array}$ \\
\hline \multicolumn{4}{|l|}{ Module C } \\
\hline MOG & {$[6 p 22.1]$} & Myelin-oligodendrocyte glycoprotein precursor & $\begin{array}{l}\text { Synaptic transmission, central nervous system } \\
\text { development }\end{array}$ \\
\hline APLP2 & [I lq24.3] & Amyloid-like protein 2 precursor (APPH) & $\begin{array}{l}\text { DNA binding, protein binding, G-protein coupled } \\
\text { receptor protein signaling pathway }\end{array}$ \\
\hline NTRI & [I I q25] & Neurotrimin precursor (hNT) & Protein binding, cell adhesion, neuron recognition \\
\hline \multicolumn{4}{|l|}{ Module D } \\
\hline DDX52 & {$[|7 q| 2]$} & $\begin{array}{l}\text { Probable ATP-dependent RNA helicase DDX52 } \\
\text { (DEAD box protein 52) }\end{array}$ & $\begin{array}{l}\text { Nucleotide binding, ATP binding, ATP-dependent } \\
\text { helicase activity }\end{array}$ \\
\hline RPL23A & {$[|7 q| \mid .2]$} & $60 S$ ribosomal protein $\mathrm{L} 23 \mathrm{a}$ & Nucleotide binding, rRNA binding, translation \\
\hline
\end{tabular}


Table 3 (Continued)

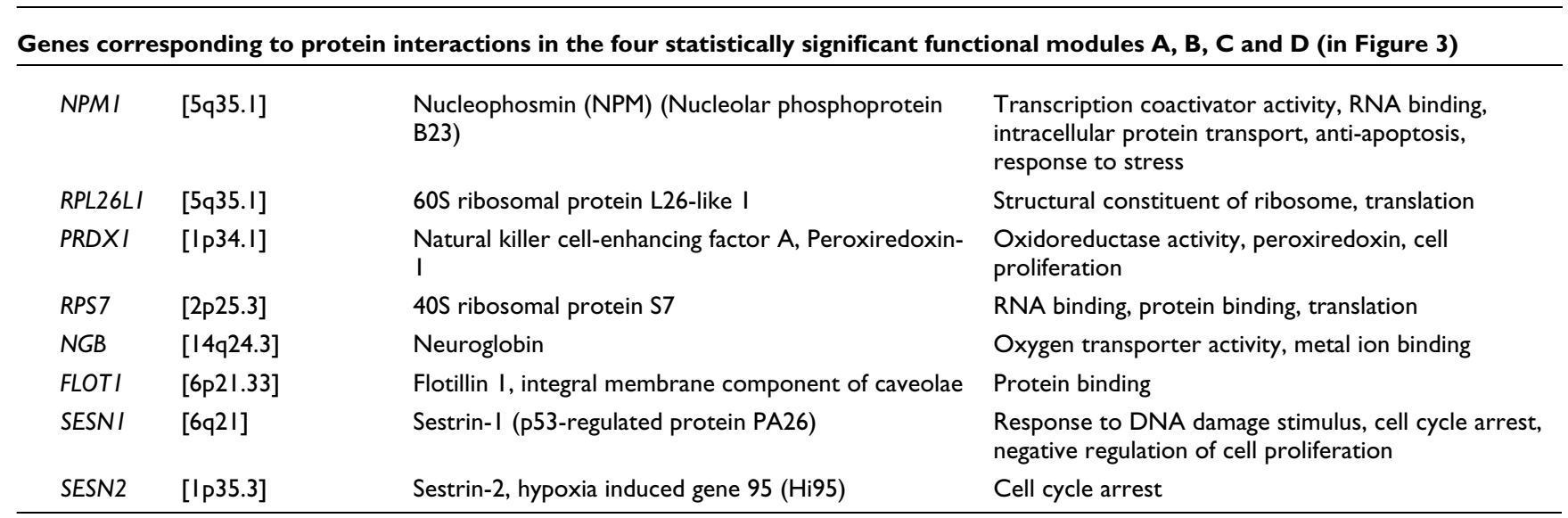

Genes corresponding to protein interactions in the four statistically significant functional modules A, B, C and D (in Figure 3). Gene names, chromosomal bands, short descriptions and gene ontology terms (molecular function and biological process) are provided.

cally interact. The resulting networks were subsequently statistically tested based on the significance of the enrichment of proteins from interacting regions. After merging results for common marker regions (TNFA and D17S798), it was possible to identify four high-confidence protein interaction sub-networks that were significantly enriched in proteins from regions that interact, thereby supporting all nine epistatic combinations identified. The constructed networks point to specific candidates, and functional relationships between the candidates. Further supporting the importance of the most significant TNFA functional module reported here (Figure 2a), a recent paper mapped the ITPR3 gene in the HLA region as a new candidate gene for T1D [40], since strong genetic association was demonstrated in two Swedish case-control cohorts.

Additionally, when all chromosome 6 markers were removed, we inferred genetic interactions for regions on chromosomes 1,2 and 5 interacting with a region on chromosome 17. A single significant functional module resulted after combining results from the three marker-pair searches that included D17S798. This functional module implicated a physical interaction between one protein from all three associated regions with a protein encoded by the RPL23A gene.

We hypothesize that the significant functional modules elucidated in this current study represent critical steps in pathways of relevance in T1D pathogenesis. The identification of known T1D associated genes supports the value of this method in searching for yet unidentified genetic and functional interactions involved in the pathogenetic processes leading to complex genetic diseases.

Most of the genes encoding proteins of the functional module networks have GO terms [1] (Table 3). However, most GO terms for molecular function and biological processes relate to each other in a simple manner and the current study supports that regulation of transcription and translation, signal transduction, ATP binding, and DNA and RNA binding are of relevance for beta-cell destruction in T1D pathogenesis (Table 3). The functional implications for the protein-protein interactions predicted strengthens the findings and highlights specific genes as candidates for further analysis. With $30 \%$ or more of human genes lacking functional annotation, existing protein interaction databases and maps are still far from being complete. Although many of the protein interactions in databases have not been rigorously tested and validated, in this work we applied very strict thresholds, including only protein interactions that were supported by various independent data sources. The functional modules presented in this study also allow for the prediction of specific candidate genes and proteins that may explain the nature of the observed genetic interactions.

\section{Conclusion}

The data presented in the current study comprise, to our knowledge, the most extensive genetic epistasis analysis in a multifactorial disease (T1D) supported by protein interaction networks. It is the first integration of genetic interactions with a systematic search for physical protein interaction networks significantly enriched in proteins from the interacting regions. The results point to specific positional candidates and cellular systems that may underlie disease susceptibility. We believe the genetic interactions produced here and the specific candidates and molecular systems highlighted by our protein network analysis will lead to new insight into the molecular pathology of T1D. Furthermore, we propose our integrative analysis as a general method for the analysis of genes and systems involved in various complex disorders.

\section{Materials and methods Genome scan data}

The data set was generated by T1DGC as part of the combined analysis of the existing T1D genome scans $[22,23,25]$. In this 


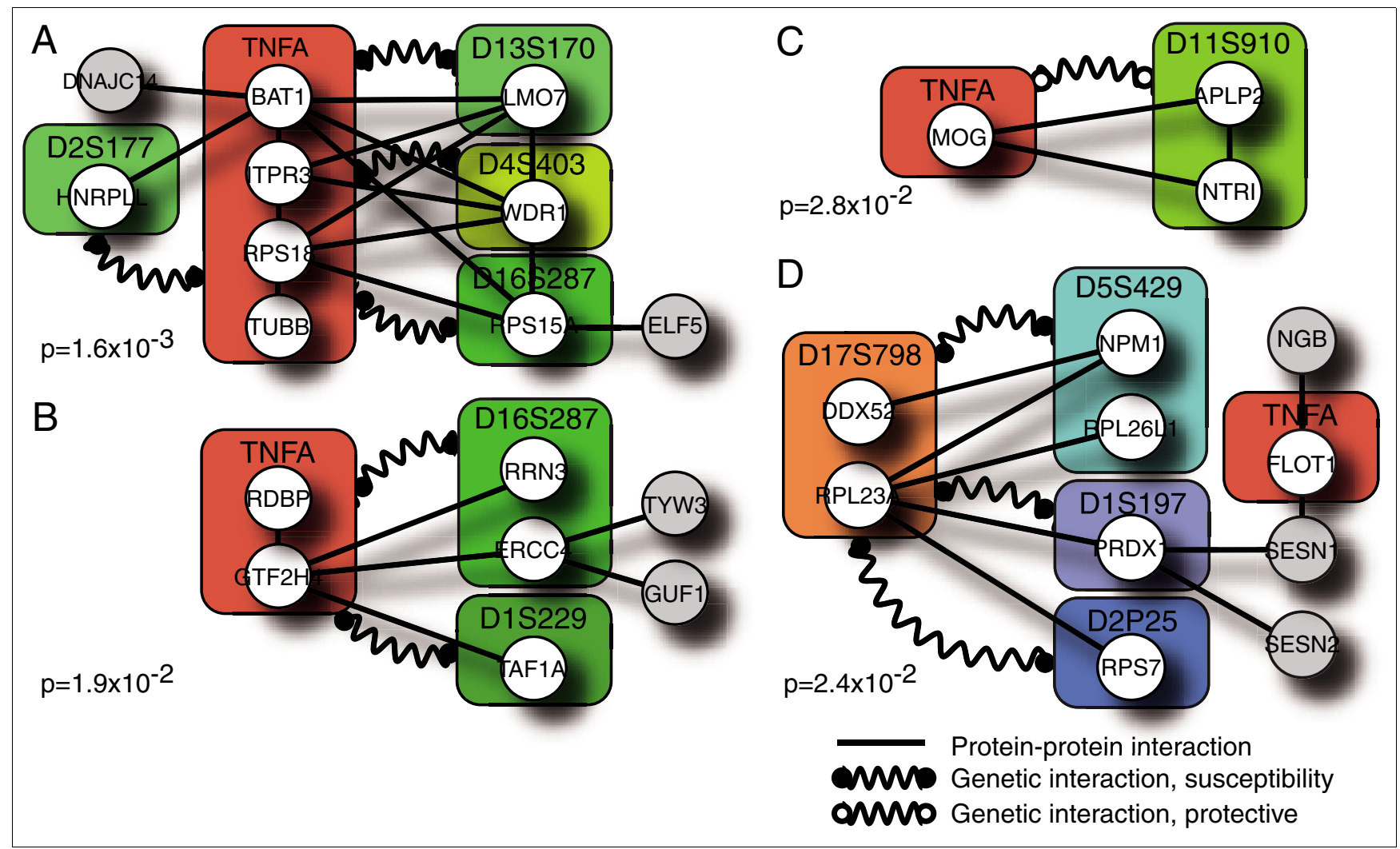

Figure 3

Significant functional modules (modules A-D). Straight lines represent validated protein-protein interactions, curved lines represent demonstrated genetic interactions (black bullets, predictive interactions; white bullets, protective interactions). Circles with gene names represent the gene encoding the protein of the interaction. Boxes are the marker regions shown to be involved in the genetic interactions and in which the genes are located.

process all genotyping data were intra-familially recoded, when possible, to show IBD status rather than exact allele calls. The Scandinavian data set comprised 392 families (411 affected sibling pairs) that were genotyped for 335 microsatellite markers. The combined UK/US data set included 763 families (910 affected sibling pairs) and genotyping of 1,283 markers. In order to analyze markers only genotyped in all data sets the number of markers was reduced to 298. Thus, the total data set used in the analysis comprised 1,321 affected sibling pairs with genotyping data on 298 markers.

\section{Data simulation for non-affected sibling pairs}

As the total data set included only a few unaffected sibling pairs and the analytical methods applied in the present study take advantage of information from non-diseased subjects [18], we simulated data for non-affected sibling pairs [1417,41]. A data matrix for unaffected sibling pairs was generated from the data matrix representing the affected sibling pairs. For each marker the number of missing values from the affected was maintained for unaffected sibling pairs. The rest of the matrix for unaffected sibling pairs was completed with values reflecting normal IBD 0,1 and 2 frequencies, that is, $0.25,0.5$ and 0.25 . No correction was made in the simulation for the actual frequency of homozygous parents. The number of unaffected sibling pairs (simulated) was two times the number of affected sibling pairs. The final data matrix then contained 1,311 affected sibling pairs and 2,622 non-affected sibling pairs.

\section{Analyses: marginal markers and interactions}

Identification of marginal markers and evaluation of interaction between markers were done as detailed previously [18], with minor modifications. Briefly, data mining algorithms and decision trees were used to predict the most informative markers. We have used the concept of marginal markers and the interactive tree model in SAS Enterprise Miner (SAS Institute Inc., Cary, NC, USA) to calculate all marginal markers using Pearson's $\chi^{2}$ statistics and corresponding $P$ value. The tree algorithm determines marginal markers as the roots (the highest level of the trees), as described previously [18]. The list of marginal markers identified by this method is produced by Pearson's $\chi^{2}$ statistics and corresponding $P$ value.

When searching for interactions between a marginal marker and markers on different chromosomes, we also used Pearson's $\chi^{2}$ statistics. Data sets were created including sibling 
pairs with TNFA IBD status $=1(T N F A=1), T N F A$ IBD status $=2(T N F A=2), D 17 S 798$ IBD status = $1(D 17 S 798=1)$ and D17S798 IBD status $=2(D 17 S 798=2)$ to search for interactions between these, the highest ranked, marginal markers and other markers. Pearson's $\chi^{2}$ statistics was then used to search for association between T1D and a marker in these individual data sets. Searching for interactions between markers on the same chromosome was not performed, because the random methods used here do not allow for linkage disequilibrium of adjacent markers on a chromosome.

\section{Human protein interaction networks}

A human protein interaction network was generated [4]. Briefly, protein interaction data were obtained from the databases BIND [42,43], MINT [44], IntAct [45], KEGG annotated protein-protein interactions (PPrel), KEGG Enzymes involved in neighboring steps (ECrel) [46] and Reactome proteins involved in the same complex, indirect complex or same or indirect reaction [47]. All human data were pooled, and to increase information interolog data (protein interactions among orthologous protein pairs in different organisms) from 17 eukaryotic organisms were also included to obtain protein-protein interaction networks [4]. We devised and thoroughly tested a global confidence score for all interactions in the network. This confidence score is constructed to take into account factors like topology of the interaction network surrounding the interaction, number of publications the interaction had been detected in, that interactions are more reliable, if they have been reproduced in more than one independent interaction experiment, and, furthermore, the experimental set-up (large- or small-scale study). Interactions from large-scale experiments generally contain more false positives than interactions from small-scale experiments [48]. Furthermore, the reliability of this score was confirmed by fitting a calibration curve of the score against overlap with a high-confidence set of about 35,00o human interactions, demonstrating that the score was a reliable measure of interaction confidence [4]. Networks were constructed from proteins in defined intervals (corresponding to the respective rules) and their first order interaction partners using interolog data in a manner similar to that described by Lehner and Fraser [49]. Proteins known to interact in other species were mapped to their human orthologs using the Inparanoid database [50,51]. In the resulting networks, each node represents all proteins encoded by a single human gene and their orthologs in other species. An edge between two nodes indicates one or more interactions between any of the proteins represented by the node. The protein interaction confidence score was implemented to use only interaction data above the interaction threshold separating 'high' from 'low' confidence interaction data. This threshold was found by using a genetic algorithm on the interaction network to obtain the optimal threshold for signal to noise ratio [4].

To further reduce noise in the networks we also devised a network score, implemented to retrieve sub-networks enriched in proteins from the selected regions that interact directly or through significant linker proteins (that is, proteins that connect proteins from the selected regions, but are not in any of the selected regions themselves). The network score reflects the amount of interaction partners allowed for each linker protein for it to be included in relation to the number of interaction partners from the selected regions. The score is calculated for every protein and is the result of 'number of interactions with input proteins' divided by 'total interactions' for each protein, making networks consisting of proteins with many interactions less important and reducing noise from highly interacting proteins from unselected regions in the genome. A very stringent threshold-score of 0.5 was used.

Positional genes and their corresponding proteins were obtained from the University of California Santa Cruz (UCSC) genome browser using 'Genes and Gene Prediction Tracks' [52] and 'Ensembl Genes' from the table browser [53]. For two marker rules, proteins encoded by genes from $5 \mathrm{Mb}$ on each site of the respective markers were used as input proteins. For the TNFA marker, proteins encoded by genes from an interval corresponding to the classic $\mathrm{MHC}$ region (position 29.26-33.90 Mb on chromosome 6) [29] were used.

For each protein belonging to an interval of interest, a query was made in the constructed human interaction network. Only interactions above the high-confidence threshold were maintained. Cytoscape version 2.3.1 was used to visualize the resulting networks [54]. Genes were classified according to GO terms [1].

\section{Statistical assessment of functional modules}

In an effort to determine the significance of the putative functional modules, we empirically estimated the probability of observing as many or more marker interval genes $\left(n_{i}\right.$ and $n_{j}$ for interval $i$ and $j$ ) in modules of size $N$ or smaller in our protein interaction network $G$, that is:

$$
P\left(x_{i} \geq n_{i}, x_{j} \geq n_{j}, X \leq N \mid G\right) .
$$

This probability was estimated for each module with $n_{i}>0$ and $n_{j}>0$ found for queries based on genes from one of the nine 2-interval genetic interactions. Estimates were derived from the size and number of modules discovered from 100,000 random queries. Random queries were constructed from genes selected from random interval pairs with the same number of genes as in the two genetically interacting marker intervals. Random intervals were defined from consecutive genes on a chromosome. As each query generates a varying number of modules (connected components), the probability estimates were calculated from the frequency of queries that result in one or more connected components containing $x_{i} \geq$ $n_{i}$ and $x_{j} \geq n_{j}$ genes from random interval $i$ and $j$, respectively, with total number of $X \leq N$ genes. 
After merging all connected components from the nine different 2-interval queries, six modules were found to contain genes from three or more intervals. For each of these $k$-interval modules, a new set of 100,000 random queries were performed with $k$ random intervals of the same sizes as the actual intervals. Probabilities were estimated in the same way as before but now based on gene counts from $k$ intervals where $k$ ranged from 3 to 5 .

\section{Abbreviations}

GO, Gene Ontology; HLA, human leukocyte antigen; IBD, identical by descent; MHC, major histocompatibility complex; T1D, type 1 diabetes; T1DGC, Type 1 Diabetes Genetics Consortium; TNF, tumor necrosis factor.

\section{Authors' contributions}

Basic idea and protocol formation: RB and FP. Data mining and decision tree analyses: MA, RB and FP. Analysis and interpretation of gene-gene interaction data: RB, MA and FP. Development of integrative system for protein-protein interactions: ZMS, KL, EOK, PÍO and SB. Construction of proteinprotein interaction networks: ZMS, KL, CTW, EOK, PÍO and SB. Development of statistical method for ranking of networks: CTW. Interpretation of protein-protein interaction network data: RB, ZMS, KL, CTW and FP. Manuscript preparation: $\mathrm{RB}$ with contributions from all authors, mainly from KL, CTW, ZMS, JN and FP.

\section{Acknowledgements}

This research utilizes resources provided by the Type I Diabetes Genetics Consortium, a collaborative clinical study sponsored by the National Institute of Diabetes and Digestive and Kidney Diseases (NIDDK), National Institute of Allergy and Infectious Diseases (NIAID), National Human Genome Research Institute (NHGRI), National Institute of Child Health and Human Development (NICHD), and Juvenile Diabetes Research Foundation International (JDRF) and supported by UOI DK0624I8. Furthermore, the Foundation of 17-12-1981, The Aase and Ejnar Danielsen Foundation, The Sehested Hansen Foundation, The AP Moller Foundation, The European Foundation for the Study of Diabetes/Juvenile Diabetes Research Foundation International/Novo Nordisk partnership, the EU BioSapiens (NoE), FP6, contract no.: LSHG-CT-2003-503265 and the Danish Technical Research Council are acknowledged for their support. We acknowledge Olga Rigina for maintaining and updating the protein interaction data warehouse at CBS and Tianshun Ye for contributing to the development of the protein interaction scoring system.

\section{References}

I. The Gene Ontology [http://www.geneontology.org]

2. Franke L, van-Bakel H, Fokkens L, de-Jong ED, Egmont-Petersen M, Wijmenga $C$ : Reconstruction of a functional human gene network, with an application for prioritizing positional candidate genes. Am J Hum Genet 2006, 78:101 I-1025.

3. Bork P, Dandekar T, Diaz-Lazcoz Y, Eisenhaber F, Huynen M, Yuan Y: Predicting function: from genes to genomes and back. J Mol Biol 1998, 283:707-725.

4. Lage K, Karlberg E, Størling Z, Òlason P, Pedersen A, Rigina O, Hinsby $A$, Tümer $Z$, Pociot $F$, Tommerup $N$, et al.: A human phenomeinteractome network of protein complexes in genetic disorders. Nat Biotechnol 2007, 25:309-316.

5. Gandhi TKB, Zhong J, Mathivanan S, Karthick L, Chandrika KN,
Mohan SS, Sharma S, Pinkert S, Nagaraju S, Periaswamy B, et al.: Analysis of the human protein interactome and comparison with yeast, worm and fly interaction data sets. Nat Genet 2006, 38:285-293.

6. Lim J, Hao T, Shaw C, Patel AJ, Szabo G, Rual J-F, Fisk CJ, Li N, Smolyar A, Hill DE, et al:: A protein-protein interaction network for human inherited ataxias and disorders of Purkinje cell degeneration. Cell 2006, I25:80I-8I4.

7. Buhler J, Owerbach D, Schaffer A, Kimmel M, Gabbay K: Linkage analyses in type-I diabetes-mellitus using caspar, a software and statistical program for conditional analysis of polygenic diseases. Hum Hered 1997, 47:211-222.

8. Cox N, Frigge M, Nicolae D, Concannon P, Hanis C, Bell G, Kong A: Loci on chromosomes 2 (NIDDMI) and 15 interact to increase susceptibility to diabetes in Mexican Americans. Nat Genet 1999, 21:213-215.

9. Farrall M: Affected sibpair linkage tests for multiple linked susceptibility genes. Genet Epidem 1997, I4:103-II5.

10. Cordell H, Wedig G, Jacobs K, Elston R: Multilocus linkage tests based on affected relative pairs. Am J Hum Genet 2000, 66: $1273-1286$.

II. van Heel DA, Dechairo BM, Dawson G, McGovern DPB, Negoro K, Carey AH, Cardon LR, Mackay I, Jewell DP, Lench NJ: The IBD6 Crohn's disease locus demonstrates complex interactions with CARD 15 and IBD5 disease-associated variants. Hum Mol Gen 2003, I 2:2569-2575.

12. Cordell H, Todd J, Bennett S, Kawaguchi Y, Farrall M: Two-locus maximum lod score analysis of a multifactorial trait: joint consideration of IDDM2 and IDDM4 with IDDMI in type I diabetes. Am J Hum Genet 1995, 57:920-934.

13. Cordell HJ, Todd JA, Hill NJ, Lord CJ, Lyons PA, Peterson LB, Wicker LS, Clayton DG: Statistical modeling of interlocus interactions in a complex disease: rejection of the multiplicative model of epistasis in type I diabetes. Genetics 200I, I 58:357-367.

14. Ritchie M, White B, Parker J, Hahn L, Moore J: Optimization of neural network architecture using genetic programming improves detection and modeling of gene-gene interactions in studies of human diseases. BMC Bioinformatics 2003, 4:28.

15. Marinov $M$, Weeks $D$ : The complexity of linkage analysis with neural networks. Hum Hered 200I, 5 I: 169-176.

16. Curtis D, North $B$, Sham P: Use of an artificial neural network to detect association between a disease and multiple marker genotypes. Ann Hum Gen 200I, 65:95-107.

17. Lucek P, Hanke J, Reich J, Solla S, Ott J: Multi-locus nonparametric linkage analysis of complex trait loci with neural networks. Hum Hered 1998, 48:275-284.

18. Pociot F, Karlsen AE, Pedersen CB, Aalund M, Nerup J: Novel analytical methods applied to type I diabetes genome scan data. Am J Hum Genet 2004, 74:647-660.

19. Risch N: Linkage strategies for genetically complex traits. I. Multilocus models. Am J Hum Genet 1990, 46:222-228.

20. Risch N: Linkage strategies for genetically complex traits. II. The power of affected relative pairs. Am J Hum Genet 1990, 46:229-24I.

21. Risch N: Linkage strategies for genetically complex traits. III. The effect of marker polymorphism on analysis of affected relative pairs. Am J Hum Genet 1990, 46:242-253.

22. Nerup J, Pociot F, European Consortium for IDDM genome studies: A genomewide scan for type I-diabetes susceptibility in Scandinavian families: Identification of new loci with evidence of interactions. Am J Hum Genet 200I, 69:130I-1313.

23. Cox NJ, Wapelhorst B, Morrison VA, Johnson L, Pinchuk L, Spielman RS, Todd JA, Concannon P: Seven regions of the genome show evidence of linkage to type I diabetes in a consensus analysis of 767 multiplex families. Am J Hum Genet 200I, 69:820-830.

24. Type I Diabetes Genetics Consortium [http://www.tldgc.org]

25. Concannon P, Erlich H, Julier C, Morahan G, Nerup J, Pociot F, Todd J, Rich S: Type I diabetes - evidence for susceptibility loci from four genome-wide linkage scans in I,435 multiplex families. Diabetes 2005, 54:2995-300I.

26. Delepine M, Pociot F, Habita C, Hashimoto L, Froguel P, Rotter J, Cambon-Thomsen A, Deschamps I, Djoulah S, Weissenbach J, et al.: Evidence of a non-MHC susceptibility locus in type I diabetes linked to HLA on chromosome 6. Am J Hum Genet 1997, 60:174-187.

27. Bergholdt R, Nerup J, Pociot F: Fine mapping of a region on chromosome 2 I q2 I. I I-q22.3 showing linkage to type I diabetes. J Med Genet 2005, 42: 17-25. 
28. Larsen ZM, Johannesen J, Kristiansen OP, Nerup J, Pociot F, Danish I, Epidemiology and Genetics Group, Danish SGoliC: Evidence for linkage on chromosome 4 p I6.I in type I diabetes Danish families and complete mutation scanning of the WFSI (Wolframin) gene. Diabet Med 2004, 2 1:218-222.

29. TIDBase [http://www.t I dbase.org]

30. MHC Sequencing Consortium: Complete sequence and gene map of a human major histocompatibility complex. Nature 1999, 401:921-923.

31. Carlborg O, Haley C: Epistasis: too often neglected in complex trait studies? Nat Rev Genet 2004, 5:618-625.

32. Cordell H: Epistasis: what it means, what it doesn't mean, and statistical methods to detect it in humans. Hum Mol Gen 2002, I I:2463-2468.

33. Kuida S, Beier D: Genetic localization of interacting modifiers affecting severity in a murine model of polycystic kidney disease. Genome Res 2000, 10:49-54.

34. Carlborg O, Kerje S, Schütz K, Jacobsson L, Jensen P, Andersson L: A global search reveals epistatic interaction between $Q T L$ for early growth in the chicken. Genome Res 2003, I3:4 I3-42 I.

35. Kim J, Sen S, Avery C, Simpson E, Chandler P, Nishina P, Churchill G, Naggert J: Genetic analysis of a new mouse model for noninsulin-dependent diabetes. Genomics 2001, 74:273-286.

36. Stranger B, Forrest M, Clark A, Minichiello M, Deutsch S, Lyle R, Hunt S, Kahl B, Antonarakis S, Tavaré S, et al.: Genome-wide associations of gene expression variations in humans. PLoS Genet 2005, I:e78.

37. Morley M, Molony C, Weber T, Devlin J, Ewens K, Spielman R, Cheung V: Genetic analysis of genome-wide variation in human gene expression. Nature 2004, 430:743-747.

38. Deutsch S, Lyle R, Dermitzakis E, Subrahmanyan L, Gehrig C, Parand L, Gagnebin M, Rougemont J, Jongeneel C, Antonarakis S: Gene expression variation and expression quantitative trait mapping of human chromosome 21 genes. Hum Mol Gen 2005, | 4:374 |-3749.

39. Li J, Burmeister M: Genetical genomics: combining genetics with gene expression analysis. Hum Mol Gen 2005, I4:RI63-RI69.

40. Roach JC, Deutsch K, Li S, Siegel AF, Bekris LM, Einhaus DC, Sheridan CM, Glusman G, Hood L, Lernmark A, et al.: Genetic mapping at 3-kilobase resolution reveals inositol 1,4,5-triphosphate receptor 3 as a risk factor for type I diabetes in Sweden. Am J Hum Genet 2006, 79:6|4-627.

4I. Lucek P, Ott J: Complex trait analysis using neural networks. Am J Hum Genet 1997, 6 I: 1649.

42. Alfarano C, Andrade CE, Anthony K, Bahroos N, Bajec M, Bantoft K, Betel D, Bobechko B, Boutilier K, Burgess E, et al.: The Biomolecular Interaction Network Database and related tools 2005 update. Nucleic Acids Res 2005, 33:D4 18-424.

43. Bader GD, Betel D, Hogue CW: BIND: the Biomolecular Interaction Network Database. Nucleic Acids Res 2003, 3 I:248-250.

44. Zanzoni A, Montecchi-Palazzi L, Quondam M, Ausiello G, HelmerCitterich M, Cesareni G: MINT: a Molecular INTeraction database. FEBS Lett 2002, 5 I 3:135-140.

45. Hermjakob H, Montecchi-Palazzi L, Lewington C, Mudali S, Kerrien S, Orchard S, Vingron M, Roechert B, Roepstorff P, Valencia A, et al:: IntAct: an open source molecular interaction database. Nucleic Acids Res 2004, 32:D452-455.

46. Kanehisa $M$, Goto $S$, Hattori $M$, Aoki-Kinoshita KF, Itoh M, Kawashima S, Katayama T, Araki M, Hirakawa M: From genomics to chemical genomics: new developments in KEGG. Nucleic Acids Res 2006, 34:D354-D357.

47. Joshi-Tope G, Gillespie M, Vastrik I, D'Eustachio P, Schmidt E, deBono B, Jassal B, Gopinath GR, Wu GR, Matthews L, et al.: Reactome: a knowledgebase of biological pathways. Nucleic Acids Res 2005, 33:D428-D432.

48. von-Mering C, Krause R, Snel B, Cornell M, Oliver SG, Fields S, Bork $\mathrm{P}$ : Comparative assessment of large-scale data sets of protein-protein interactions. Nature 2002, 41 7:399-403.

49. Lehner B, Fraser AG: A first-draft human protein-interaction map. Genome Biol 2004, 5:R63.

50. Remm M, Storm CEV, Sonnhammer ELL: Automatic clustering of orthologs and in-paralogs from pairwise species comparisons. J Mol Biol 2001, 3 I 4: 1041-1052.

5I. O'Brien KP, Remm M, Sonnhammer ELL: Inparanoid: a comprehensive database of eukaryotic orthologs. Nucleic Acids Res 2005, 33:D476-480.
52. UCSC Genome Bioinformatics [http://www.genome.ucsc.edu]

53. Ensembl Genome Browser [http://www.ensembl.org]

54. Shannon P, Markiel A, Ozier O, Baliga NS, Wang JT, Ramage D, Amin $\mathrm{N}$, Schwikowski B, Ideker T: Cytoscape: a software environment for integrated models of biomolecular interaction networks. Genome Res 2003, I 3:2498-2504. 